Correspondance: Commission consultative c/o ASSM Petersplatz 13 4051 Bâle mail@samw.ch
La collaboration entre les médecins et l'industrie est une pratique depuis longtemps établie, qui généralement contribue au développement des connaissances.

Toutefois, une telle coopération peut générer des conflits d'intérêts et des dépendances, voire des problèmes légaux.

Pour les médecins, qu'ils soient chercheurs, cliniciens ou praticiens, la collaboration avec l'industrie soulève non seulement une question légale, mais surtout une question fondamentale d'éthique professionnelle.

En dressant eux-mêmes des garde-fous destinés à préciser et compléter les réglementations existantes, les médecins soulignent leur volonté d'indépendance et assoient leur crédibilité.

\section{Et vous, comment} procédez-vous?
En 2006, I’Académie Suisse des Sciences Médicales avait publié des directives "Collaboration corps médical - industrie». Celles-ci stipulent entre autres:

\section{3.}

Tous les essais cliniques sont répertoriés dans un registre central.

\section{Cet enregistrement vise}

- à garantir la publication correcte et complète des résultats, et

- à exclure des changements ultérieurs contraires aux GCP dans le protocole d'essai.

Ce registre doit être tenu par une institution publique qualifiée et être accessible au public. Il doit contenir les éléments clés relatifs à un essai.

Les directives peuvent être consultées sous www.samw.ch/Ethique.

Un set de présentation avec un modèle d'exposé ainsi que d'autres documents sont également disponibles sous ce lien. Pour toute question ou précision, la Commission consultative pour la mise en oeuvre des directives «Collaboration

corps médical - industrie» se tient volontiers à votre disposition.

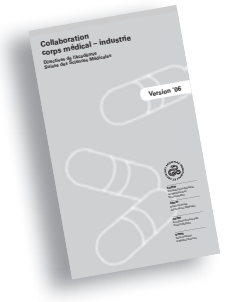

